\title{
Physical Abuse During Pregnancy : An Experience of 139 cases
}

\author{
N F Khan', N Islam², F M Chowdhury ${ }^{3}$, I Asadullah ${ }^{4}$
}

Abstract

Objective : To assess pattern and proportion of physical abuse during pregnancy in relation to socio demographic characteristics of abused women.

Material \& Methods : A descriptive type of cross sectional study was conducted in RADDA-MCH-FP Center, Mirpur-10, Dhaka during January to July 2011. A total of 139 pregnant women of reproductive age group (15-45) year's who visited for antenatal check up were selected purposely. Data were collected through face to face interview using pretested structured questionnaire.

Results : Socio demographic characteristics of respondents revealed that mean age $22.20 \pm 39$ years and husbands mean age $28.57 \pm$ 5.39 years. Highest number of respondents education upto SSC level (49.6\%). $74.8 \%$ were housewife; socio economic status was lower middle class, $18.7 \%$ had history of dowry. The proportion of physical abuse during pregnancy was $31.6 \%$. Among them $15.83 \%$ had mixed type of abuse. Highly significant association was found with dowry (p 0.00 ) and planed pregnancy (p 0.006). A statistically significant association was found between respondent's education level and physical abused $(p<0.05)$ indicating respondents had low level of education increase physical abuse. A statistically significant association also found with residence (urban/slum) $(p<0.05)$ and who had history of dowry $(p<0.05)$.

Conclusion : Physical abuse during pregnancy was mostly seen in the respondent who belongs to slum area and had low educational level.

${ }^{2}$ Dr. Nazrul Islam Ph.D

Associate Professor

Head of Department

Reproductive \& Child Health

NIPSOM, Mohakhali

${ }^{3}$ Dr. Farhana Masum Chowdhury MBBS, MPH (Epi)

Assistant Professor

Community Medicine

MARKS Medical College \&

Hospital, Dhaka

${ }^{4}$ Dr. Ishtiaq Asadullah

Lecturer

Community Medicine

Holy Family Red Crescent

Medical College \& Hospital Dhaka

\section{Correspondence}

Dr. Nishat Farhana Khan

MBBS, MPH (RCH)

Assistant Professor,

Community Medicine

MARKS Medical College \&

Hospital, Dhaka.

Email: nishat1907@gmail.com
Therefore necessary step should be taken by health system as well as government to prevent physical abuse during pregnancy.

\section{Introduction}

Physical abuse towards pregnant women cuts across societies, classes, education, income, ethnicity and age in developed and developing countries of the world. It is a gross violation of human rights and has many far reaching consequences for a woman and her fetus including serious social and health problems. It is clear from the research that abuse towards woman during pregnancy is an issue that cuts across countries, however prevalence varies from country to country and even within countries ${ }^{1}$.

In Bangladesh abuse has been recognized one of the leading causes of injury related death among pregnant woman. Intimate partner violence is not a new phenomenon and usually results in serious health problem in woman. It is estimated that 14 percent of maternal deaths are associated with violence. Inclusion of this indicator when monitoring the MDGs will help raise awareness of this national problem². Sometimes domestic violence begins or increases during pregnancy remain unseen. Most of the Physical abuse and ill treatment by in-laws during and after pregnancy is a common occurrence in India ${ }^{3}$.

Most of the research on violence during pregnancy focuses on abuse by past or current intimate partners. Multiple social, economic, cultural, biological and environmental factors contribute to violence toward women during pregnancy. Low socioeconomic status has consistently been identified as a risk factor for violence during pregnancy. Women's low level of education is important contributing factor. Finally, young pregnant women are more likely than those who are older to be abused. In Bangladesh and elsewhere, violence has been recognized as one of the leading causes of injury-related deaths among pregnant women. About one in 10 women had ever been abused during pregnancy ${ }^{4}$.

The majority of abused women remained silent about their experience because of the high acceptance of violence within society, fear of repercussion, tarnishing family honor and own reputation, jeopardizing children's future, and lack of an alternative place to stay. Violent behaviors such as beating, pushing, slapping or throwing things by family members are considered domestic violence ${ }^{5}$.

Physical abuse of woman during pregnancy is commonly recognized as an important public health problem because of its morbidity, mortality and long term impact of woman's \& child health. In many countries a substantial proportion of women that experience physical abuse during pregnancy by their husband and other family members ${ }^{6}$.

Considering the impact of physical abuse during pregnancy, this study was undertaken to find out the proportion of physical abuse during pregnancy, pattern of physical abuse and also socio demographic characteristics of abused woman.

\section{Materials \& Methods}

A descriptive type of cross sectional study was conducted among the pregnant women. The study was conducted from January 2011 - July 2011. For collecting data formal permission was obtained from the concern authority of RADDA-MCH-FP center, Mirpur-10. A total of 139 pregnant women of reproductive age group (15 - 45 years) who visited ANC center where selected by purposive sampling. After taking proper confidentiality and privacy, data were collected from the respondents though face to face interview and observation by using a pretested questionnaier. All data forms were checked on regular basis for accuracy, consistency and completeness. Statistical analysis was done with the help of the computer using Statistical Package for Social Science (SPSS), Version-16 program.

\section{Result}

A Cross Sectional study conducted Mirpur - 10 in Dhaka city among 139 with a view to find out proportion of physical abuse during pregnancy. 
Table I : Socio-demographic profile of the respondents $(n=139)$

\begin{tabular}{|c|c|c|}
\hline Respondent's age in years & Frequency & Percentage \\
\hline $15-20$ & 63 & 45.3 \\
\hline $21-25$ & 71 & 51.1 \\
\hline$\geq 26$ & 5 & 3.6 \\
\hline \multicolumn{3}{|l|}{ Mean \pm SD $=22.20 \pm 3.9$} \\
\hline \multicolumn{3}{|l|}{ Husband age in years } \\
\hline $15-20$ & 4 & 2.9 \\
\hline $21-25$ & 102 & 73.4 \\
\hline$\geq 26$ & 33 & 23.7 \\
\hline \multicolumn{3}{|l|}{ Mean \pm SD $=28.57 \pm 3.9$} \\
\hline \multicolumn{3}{|l|}{ Respondent's level of education } \\
\hline Illiterate & 2 & 1.4 \\
\hline Primary & 25 & 18.0 \\
\hline SSC & 69 & 49.6 \\
\hline Hon. and above & 10 & 7.2 \\
\hline Others & 14 & 10.1 \\
\hline \multicolumn{3}{|l|}{ Occupation of the respondent } \\
\hline Housewife & 104 & 74.8 \\
\hline Non gov. service & 4 & 2.9 \\
\hline Business & 4 & 2.9 \\
\hline Others & 27 & 19.4 \\
\hline \multicolumn{3}{|l|}{ Religion of Respondent } \\
\hline Muslim & 138 & $99.28 \%$ \\
\hline Hindu & 1 & $0.72 \%$ \\
\hline Total & 139 & 100.0 \\
\hline \multicolumn{3}{|l|}{ Monthly family income } \\
\hline$\leq 5000$ & 19 & 13.7 \\
\hline $5001-10000$ & 71 & 51.1 \\
\hline$\geq 10001$ & 49 & 35.3 \\
\hline \multicolumn{3}{|l|}{ Mean \pm SD $=13577.70 \pm 12569.07$} \\
\hline \multicolumn{3}{|l|}{ Residence } \\
\hline Town & 110 & 79.1 \\
\hline Village & 1 & 0.7 \\
\hline Slum & 22 & 15.8 \\
\hline Sub Urban & 5 & 3.6 \\
\hline Others & 1 & 0.7 \\
\hline \multicolumn{3}{|l|}{ History of dowry } \\
\hline No & 113 & 81.3 \\
\hline Yes & 26 & 18.7 \\
\hline \multicolumn{3}{|l|}{ Worry about expenditure } \\
\hline No & 79 & 56.8 \\
\hline Yes & 60 & 43.2 \\
\hline
\end{tabular}

The study revealed that among 139 respondents, the mean age of respondent was $22.20 \pm 3.9$ years ranging from 16 to 37 years. Highest percentage ( $51.1 \%$ ) where in the range of $21-25$ years. The mean age of the respondent's husband was $28.57 \pm 5.39$ years ranging from 19 to 46 years. The highest percentage (73.4\%) where in the range of $21-25$ years. Among educated respondent higher percentage $49.6 \%$ had secondary level followed by $18.0 \%$ had primary level of education. It was evident the highest percentage (74.8\%) were house wife. About $99.3 \%$ respondents were Muslim. The mean monthly family income was Tk. 13577.70 ranging from $3,000-10,000$. Highest percentage 51.1 of family has monthly income ranging from 5001-10,000 Most of the respondent 79.1 percentages lived in town, 15.8 percentages lived in slum Most of the respondent had $81.3 \%$ had no history of dowry, $18.7 \%$ had history of dowry during marriage. It shows, $56.8 \%$ had no worry about expenditure rest of $43.2 \%$ was worried about expenditure (Table- 1 ).
Figure 1: Distribution of respondents by history of abuse during pregnancy

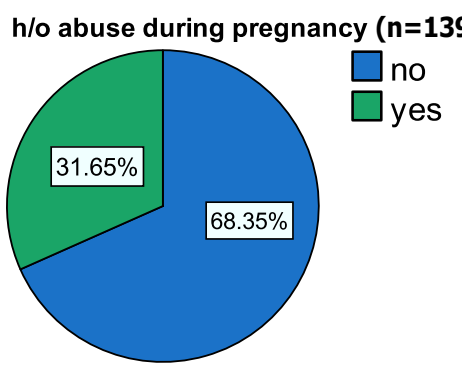

Figure 1 shows $31.65 \%$ had history of abuse during pregnancy and rest $68.35 \%$ had no history of abuse during pregnancy.

Figure 2: Distribution of respondents by pattern of abuse

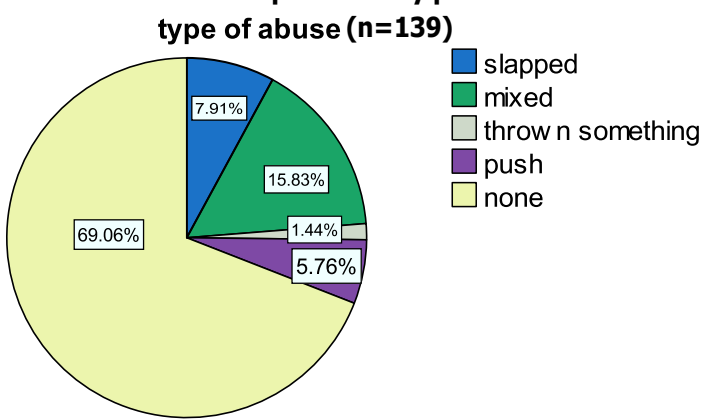

Figure 2 shows $15.83 \%$ had mixed type of abuse during pregnancy, $7.91 \%$ had slapped, $5.76 \%$ had pushed, $1.44 \%$ had thrown something on her rest of $69.06 \%$ had no history of abuse.

Figure 3: Distribution of abused according to Abuser

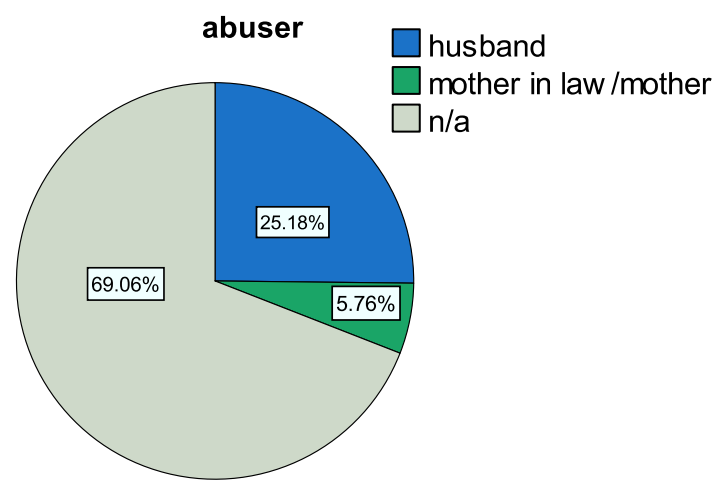

Figure 3 shows Among the respondents $25.18 \%$ had physical abused by husband during pregnancy, $5.7 \%$ had abused by mother in laws and rest of $69.06 \%$ had no history of physical abuse.

Table II: Association of physical abuse during pregnancy with residence and level of education

\begin{tabular}{|c|c|c|c|c|}
\hline \multirow[t]{2}{*}{ Category } & \multicolumn{2}{|c|}{ Physical abuse } & \multirow[t]{2}{*}{$x^{2}$} & \multirow[t]{2}{*}{ P value } \\
\hline & Yes n (\%) & No n (\%) & & \\
\hline \multicolumn{5}{|l|}{ Residence } \\
\hline \multirow{2}{*}{$\begin{array}{l}\text { Urban } \\
\text { Slum }\end{array}$} & $32(27.8)$ & $83(72.2)$ & \multirow{2}{*}{4.513} & \multirow{2}{*}{0.034} \\
\hline & $12(50.0)$ & $12(50.0)$ & & \\
\hline \multicolumn{5}{|c|}{ Level of education } \\
\hline \multirow{2}{*}{$\begin{array}{l}\text { Up to primary } \\
\text { Above primary }\end{array}$} & $24(41.4)$ & $34(58.6)$ & \multirow{2}{*}{4.351} & \multirow{2}{*}{0.037} \\
\hline & $20(24.7)$ & $61(75.3)$ & & \\
\hline
\end{tabular}

* percentage in parenthesis 
Among the slum $50 \%$ had history of physical abuse. Whereas among the urban group $27.8 \%$ had history of physical abuse. The result showed statistically significant $(P<0.05)$. The physical abuse differs with relation with education level. Lower the educational level, higher the rate of physical abuse. There was significant association between education and physical abuse ( $p<0.05)$.

Table III: Association of physical abuse during pregnancy with planned pregnancy and history of dowry

\begin{tabular}{|c|c|c|c|c|}
\hline \multirow[t]{2}{*}{ Category } & \multicolumn{2}{|c|}{ Physical abuse } & \multirow[t]{2}{*}{$x^{2}$} & \multirow[t]{2}{*}{$P$ value } \\
\hline & Yes n (\%) & No $n(\%)$ & & \\
\hline \multicolumn{5}{|c|}{ Planned Pregnancy } \\
\hline No & $30(42.3)$ & $41(57.7)$ & \multirow{2}{*}{7.539} & \multirow{2}{*}{0.006} \\
\hline Yes & $14(20.6)$ & $54(79.4)$ & & \\
\hline \multicolumn{5}{|c|}{ History of Dowry } \\
\hline No & $25(22.1)$ & $88(77.9)$ & \multirow{2}{*}{25.365} & \multirow{2}{*}{0.000} \\
\hline Yes & $19(73.1)$ & $7(26.9)$ & & \\
\hline
\end{tabular}

*percentage in parenthesis

The respondents who had unplanned pregnancy also had physical abuse. The unplanned pregnancy showed significant association with physical abuse $(p<0.05)$. Among the respondents who had history of dowry $73.1 \%$ had history of physical abuse. Whereas the respondent who had no history of dowry $22.1 \%$ had history of physical abuse. The history of dowry of respondent showed statistically highly significant $(p<0.05)$

\section{Discussion}

In this study mean age of respondents was $22.20 \pm 3.9$ years (Range 15-49 years) and $49.6 \%$ had secondary level of education. 44 (31\%) of 139 women had experience physical abuse during pregnancy. This result is mostly similar to the study of The Multi-country Study on Women's Health and Domestic Violence against Women, sponsored by the World Health Organization, between 2000 and $2003^{7,8}$.

Study shows that among the pregnant women interviewed $99.3 \%$ were belong to Muslim and $0.7 \%$ was Hinduism. That had similarity with Ruchira Tabassum Naved et-al in her study finding that rural Muslim women were more likely than rural women of other religions to be abused during pregnancy ${ }^{4}$.

Among the recently pregnant women interviewed, negligible (1.4\%) were illiterate, among educated higher percentage $49.6 \%$ had secondary level of education. Female literacy rate in Bangladesh is 58\% (according to Bangladesh MDG progress report 2009). In the present study this rate was $98.6 \%$. Dissimilarity was due to there were education for female, compulsory primary education, food for education program and decreased dropout rate from school. In this study the primary level of education significantly associated with physical abuse during pregnancy. It was mostly similar to the study of Dian K. Bohn, Julie G. Teben et-al ${ }^{9}$.

Among the recently pregnant women interviewed, higher number $74.8 \%$ were housewife and $25.2 \%$ were engaged in service. This result was due to the fact that social and cultural melieo does not allow women as well as pregnant women to work out side the home. In the present study mean monthly family income was Tk. 13577.70. It was due to maximum respondents husband were doing business and other jobs. In this study income not statistically significant with physical abuse during pregnancy but in study of Dian K. Bohn showed that decrease income significantly related to abuse during pregnancy ${ }^{9}$.

About $81.3 \%$ respondent had no history of taking dowry during marriage and $18.7 \%$ had history of taking dowry during marriage. It showed age at marriage dowry demand had significant $(p<0.05)$ relationship with physical abuse during pregnancy. It similar to study of Lagos Metropolis, Nigeria shows that, dowry demand involvement, age at marriage, past history of abuse and spousal communication are the most important predictors of physical spousal abuse of women during pregnancy ${ }^{1}$.

In recent study about $15.83 \%$ had history of mixed type of abuse. It similar with according to CDC pattern of violence ${ }^{10}$. Study of Bertha Alicia Guaderrama de Moseson shows the pattern of abuse similar with the recent study ${ }^{11}$. Hitting was mostly done with the use of hand $(85.4 \%)$, followed by stick $(63.5 \%)$, and kicking (51\%) alone or in combination. The study reported that $20 \%$ of women were physically abused by their husbands during pregnancy and $2.6 \%$ by other family members as well. About, $13.7 \%$ were throttled by their husbands and $2.1 \%$ by other family members ${ }^{12}$.

In this study $21.58 \%$ respondents had simple type of injury. Only $8.60 \%$ had severe type of injury. GUO Su-fang, WU Jiu-ling et-al in china study shows that, $20 \%$ of physical abuse involved punching or beating leading to head/internal injury or involved wounding by means of a weapon. These results indicated that most cases of physical abuse were not severe ${ }^{13}$.

In recent study shows $25.18 \%$ husband was abuser. It was similar with the study In Alaska showed, $78 \%$ of abuse women identified their husband of partner as the main physical abuse perpetrator ${ }^{8}$. Study of Bertha Alicia Guaderrama de Moseson shows the prevalence of intimate partner violence in pregnancy (IPVP) in the United States was estimated as between $4 \%$ and $8 \%$ of all pregnancies ${ }^{11}$.

\section{Conclusion}

Physical abuse during pregnancy is a serious and harmful problem. Pregnant mother and their babies stand the risk of injury from physical abuse. Abuse during pregnancy can affect women irrespective of their socio economic and demography background.

\section{References}

1. Oladeji David. "Determinants of Physical Spousal Abuse of Women During Pregnancy in Nigerian" Department of Home and Hotel Management (Child Development and family Studies Unit), Olabisi Onabanjo University, Ago-Iwoye; Published in website May 26th, 2010; http://allfamous.info/ legal/child-abuse/determinants-of-physical-spousal-abuse-of-womenduring-pregnancy-in-nigerian/

2. Government of Bangladesh and United Nations Country Team in Bangladesh. "The Millennium Development Goals, Bangladesh Progress Report 2005" year 2005 February: Page 37

3. Lisa Chedekel." Indian Women Abused By In-Laws During Pregnancy". Boston University Medical Center. 18 Aug 2010; http://www.medicalnewstoday.com/ releases/197971.php

4. Ruchira Tabassum, Naved and Lars Åke Persson. "Factors Associated with Physical Spousal Abuse of Women During Pregnancy in Bangladesh" 2008, International Family Planning Perspectives,2008,34(2):71-78

5. Dr. Mahmuda Akhter. "Domestic Violence Against Urban Married Women in Dhaka City" Student Dissertation, NIPSOM, Mohakhali, Dhaka 2003 : Page 18 (Unpublished)

6. Murat TOPBAfi, Mesut ÜNSAL, Gamze ÇAN, Aynur BACAK, fiükrü ÖZGÜN. "The Effect of Pregnancy on the Physical and Sexual Abuse of Women That Presented to a State Hospital in Trabzon, Turkey" Turk J Med Sci 2008; 38 (4): 335-342

7. World Health Organization. "WHO Multi-Country study on Woman's health and Domestic Violence against Women: Country Findings, Bangladesh" 2005: page 1-2

8. Kathy Perham-Hester and Linda Chamberlain "Domestic Violence in Alaska". Family Health Dataline; Vol 5, No 2; Page 1-4

9. Diane K. Bohn, Julie G. Tebben, and Jacquelyn C. Campbell. "Influences of Income, Education, Age, and Ethnicity on Physical Abuse Before and During Pregnancy". Jognn Clinical Research, September/October 2004; Page: 561 - 571

10. Matta kuning, Don McNeil, Virasakdi Chongsuvivatwong. "Physical Abuse During Pregnancy". Eur J Gen Med 2004; 1(2): 6-10

11. Bertha Alicia Guaderrama de Moseson, "Intimate Partner Violence During Pregnancy: Risk Factors From the Oregon Pregnancy Risk Assessment Monitoring System" A thesis Department of Public Health and Preventive Medicine and the Oregon Health and Science University School of Medicine. April 2004

12. Tania Wahed \& Abbas Bhuiya "Battered bodies \& shattered minds: Violence against women in Bangladesh" Indian J Med Res 126, October 2007, pp 341-354

13. GUO Su-fang, WU Jiu-ling, QU Chuan-yan, YAN Ren-ying. "Domestic abuse on women in China before, during, and after pregnancy." CMJ 2004; 117(3):331-336 